\title{
Exploration of charge states of balanol analogues acting as ATP-competitive inhibitors in kinases
}

\author{
Ari Hardianto ${ }^{1}$, Muhammad Yusuf ${ }^{2}$, Fei Liu ${ }^{1}$ and Shoba Ranganathan ${ }^{1 *}$ \\ From 16th International Conference on Bioinformatics (InCoB 2017) \\ Shenzhen, China. 20-22 September 2017
}

\begin{abstract}
Background: (-)-Balanol is an ATP mimic that inhibits protein kinase $C$ (PKC) isozymes and CAMP-dependent protein kinase (PKA) with limited selectivity. While PKA is a tumour promoter, PKC isozymes act as tumour promoters or suppressors, depending on the cancer type. In particular, PKC $\varepsilon$ is frequently implicated in cancer promotion, making it a potential target for anticancer drugs. To improve isozyme selectivity of balanol, exhaustive structural and activity relationship (SAR) studies have been performed in the last two decades, but with limited success. More recently, fluorination on balanol has shown improved selectivity for $\mathrm{PKC} \varepsilon$, although the fluorine effect is not yet clearly understood. Understanding the origin to this fluorine-based selectivity will be valuable for designing better balanol-based ATP mimicking inhibitors. Computational approaches such as molecular dynamics (MD) simulations can decipher the fluorine effect, provided that correct charges have been assigned to a ligand. Balanol analogues have multiple ionisable functional groups and the effect of fluorine substitutions on the exact charge state of each analogue bound to PKA and to PKC $\varepsilon$ needs to be thoroughly investigated in order to design highly selective inhibitors for therapeutic applications.
\end{abstract}

Results: We explored the charge states of novel fluorinated balanol analogues using MD simulations. For different potential charge states of these analogues, Molecular Mechanics Generalized Born Surface Area (MMGBSA) binding energy values were computed. This study suggests that balanol and the most potent fluorinated analogue (5S fluorine substitution on the azepane ring), have charges on the azepane ring (N1), and the phenolic (C6"OH) and the carboxylate $\left(\mathrm{C}^{1} 5^{\prime \prime} \mathrm{O}_{2} \mathrm{H}\right)$ groups on the benzophenone moiety, when bound to PKC $\varepsilon$ as well as PKA.

Conclusions: To the best our knowledge, this is the first study showing that the phenolate group is charged in balanol and its analogues binding to the ATP site of PKCE. Correct charge assignments of ligands are important to obtain predicted binding energy values from MD simulations that reflect experimental values. Both fluorination and the local enzymatic environment of the ATP site can influence the exact charge states of balanol analogues. Overall, this study is highly valuable for further rational design of potent balanol analogues selective to PKC $\varepsilon$.

Keywords: Kinase inhibitors, Ligand charge state, ATP mimic, Molecular modelling, Molecular dynamics simulation

\footnotetext{
* Correspondence: shoba.ranganathan@mq.edu.au

'Department of Molecular Sciences, Macquarie University, Sydney, NSW 2109,

Australia

Full list of author information is available at the end of the article
} International License (http://creativecommons.org/licenses/by/4.0/), which permits unrestricted use, distribution, and reproduction in any medium, provided you give appropriate credit to the original author(s) and the source, provide a link to the Creative Commons license, and indicate if changes were made. The Creative Commons Public Domain Dedication waiver (http://creativecommons.org/publicdomain/zero/1.0/) applies to the data made available in this article, unless otherwise stated. 


\section{Background}

(-)-Balanol (referred to as balanol) is a natural product originally isolated from the fungus Verticillium balanoides [1]. It is an ATP mimic [2] as revealed by X-ray crystallographic structures of PKA-bound balanol (1BX6) [3] and ATP (1ATP) [4]. Balanol comprises four ring structures and fully occupies the flexible ATP site (Fig. 1). The benzamide moiety (ring A) occupies the adenine subsite, whereas the azepane moiety (ring B) resides in the ribose subsite. The benzophenone moiety (rings $C$ and D) fills the triphosphate subsite.

(-)-Balanol is a competitive inhibitor of ATP but nonselective for protein kinase A (PKA) and protein kinase $C$ (PKC) isozymes [5]. PKA is known to have tumour promoting activities [6]. Similarly, PKC isozymes regulate gene expression important to the cell cycle, tumorigenesis, and metastatic progression. Most PKC isozymes, however, can act as tumour promoters or suppressors, depending on the type of cancer. For instance, in breast cancer, whereas $\mathrm{PKC} \alpha, \mathrm{PKC} \beta \mathrm{II}$, and $\mathrm{PKC} \delta$ are tumour promoters, PKC $\beta I$ suppresses the cancer [7]. On the other hand, $\mathrm{PKC} \beta \mathrm{I}$ is a promoter and $\mathrm{PKC} \delta$ is a suppressor in prostate cancer. Of the PKC isoforms, PKCe exhibits clear oncogenic activities and is a potential anti-cancer therapeutic target [7].

Designing inhibitors that are selective to an individual PKC isozyme is very challenging due to the high sequence conservation of ATP sites among PKC isozymes and also other protein kinases, in general [7]. To achieve PKC isozyme selectivity, balanol has been explored intensively in several structure and activity relationship (SAR) studies, with PKA as reference in some of these studies. These SAR studies included modifications to every part of balanol (illustrated in Fig. 1): benzamide (ring A) [8, 9], azepane (ring B) [10], and benzophenone moieties (rings $C$ and D) $[11,12]$. Modifications to the benzamide moiety emphasized the important role of $\mathrm{C5}^{\prime} \mathrm{OH}$ for PKC inhibition [8]. Derivatization studies on the benzophenone ring, which were replacement of the carboxylic group on ring D with hydrogen, esters, hydroxyl, amide, sulfonamide, or tetrazole, pointed to the importance of the acidic functional group on balanol activity $[10,11]$. Some SAR studies were performed by replacing the azepane ring with five-membered pyrrolidine ring but without substantial selectivity improvement [11].

More recently, we have successfully introduced stereospecific monofluorination (Table 1: 1a and 1c) and multiple fluorine substituents (Table 1: 1d and 1e) on the azepane moiety for the first time and measured binding affinities of these fluorinated balanol analogues to PKA and PKC isozymes [13]. Although most of the fluorinated analogues explored in this study (Fig. 2) showed either equal or reduced binding affinity compared to balanol itself (referred to as 1) across the enzyme panel (Table 1), analogue 1c, carrying a fluorine substituent at the $\mathrm{C} 5(S)$ position, improves the binding affinity and selectivity to PKCe. The introduction of a small fluorine substituent on the azepane moiety does not introduce significant size change to balanol $[14,15]$. However, fluorine can provide complex physicochemical perturbation and stereoelectronic effects that alter the overall confirmation of balanol for selective binding amongst highly homologous ATP sites of protein kinases [13].

Understanding the fluorine effect on the binding of balanol analogues to PKA as well as PKCe is an important aspect of further development of balanol-based inhibitors. A rapid way to acquire this understanding is by computational approaches. Our earlier computational investigation using a molecular docking approach showed that, compared to unsubstituted balanol, additional protein-ligand interactions in the ATP site can be conferred by fluorination [13]. In addition to molecular docking, molecular dynamics (MD) simulations can provide a deeper understanding of the binding of fluorinated balanol analogues to PKA as well as to PKCE. An MD simulation allows the investigation of intermolecular interaction dynamics between the ligand and residues at the binding site [16]. It also provides insight into the conformational space explored by the ligand during binding as well as the binding energy from ensemble conformations. Furthermore, since protein kinases are flexible

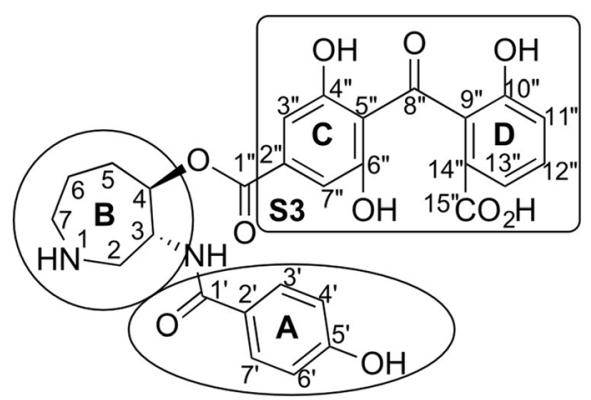

$$
\begin{aligned}
\mathrm{S} 1= & \text { adenine } \\
& \text { binding subsite } \\
\mathrm{S} 2= & \text { ribose } \\
& \text { binding subsite } \\
\mathrm{S} 3= & \text { triphosphate } \\
& \text { binding subsite }
\end{aligned}
$$

Fig. 1 Balanol structure, decomposed into subsites based on structural overlay with ATP 
Table 1 Table 1 Dissociation constant $\left(K_{d}\right)$ and binding affinity values of balanol analogues to PKA or PKC $\varepsilon$

\begin{tabular}{|c|c|c|c|c|c|}
\hline Protein kinase & $\begin{array}{l}\text { (-)-balanol, } \\
\mathbf{1}\end{array}$ & $\begin{array}{l}\text { (6S)-F analogue, } \\
\mathbf{1 a}\end{array}$ & $\begin{array}{l}\text { (5S)-F analogue, } \\
\text { 1c }\end{array}$ & $\begin{array}{l}(6 R, S) \text {-dif analogue, } \\
\mathbf{1 d}\end{array}$ & $\begin{array}{l}\text { (5S)-(6R,S)-trif analogue, } \\
\mathbf{1 e}\end{array}$ \\
\hline & \multicolumn{5}{|c|}{$K_{d}(\mathrm{nM})$} \\
\hline PKA & $5.9 \pm 0.5$ & $7.9 \pm 0.5$ & $6.4 \pm 0.1$ & $9.2 \pm 0.8$ & $43 \pm 4$ \\
\hline \multirow[t]{2}{*}{$\mathrm{PKC} \varepsilon$} & $0.73 \pm 0.06$ & $19 \pm 8$ & $0.4 \pm 0.02$ & $110 \pm 19$ & $38 \pm 9.5$ \\
\hline & \multicolumn{5}{|c|}{$\Delta G_{\text {experiment }}^{\circ}\left(\mathrm{kcal} . \mathrm{mol}^{-1}\right)$} \\
\hline PKA & $-11.30 \pm 0.05$ & $-11.12 \pm 0.03$ & $-11.25 \pm 0.01$ & $-11.03 \pm 0.05$ & $-10.11 \pm 0.05$ \\
\hline $\mathrm{PKC \varepsilon}$ & $-12.54 \pm 0.05$ & $-10.60 \pm 0.21$ & $-12.90 \pm 0.03$ & $-9.55 \pm 0.09$ & $-10.19 \pm 0.14$ \\
\hline
\end{tabular}

enzymes capable of induce-fit interactions [2], MD simulations provide an opportunity to investigate the effect of this plasticity in ligand binding [17] to PKC and PKA.

In MD simulations, the charge state of each ligand needs to be specified a priori [18]. Balanol has several polar protic functional groups in its structure (Fig. 1) [1], comprising a secondary amine on the azepane ring (ring B), a carboxylic acid group on the benzophenone ring (ring D), and four phenolic groups on the benzamide (ring $\mathrm{A}$ ) and the benzophenone (rings $\mathrm{C}$ and $\mathrm{D}$ ) moieties. These basic and acidic functional groups potentially adopt multiple charge states depending on the $\mathrm{pH}$ of the ATPbinding site. Charge state variation of balanol were computationally investigated in a previous study [19]. The study suggested that charges on the carboxylic (ring D) and the amine (ring A) would be necessary for balanol binding to the ATP site of PKA, while the negative charges on phenolic groups were considered to have only a small contribution to binding affinity and were therefore considered neutral.

The charge states of fluorinated balanol analogues may differ from that of the parent compound, balanol. The introduction of a highly electronegative fluorine substituent may change the charge state profile of balanol analogues. Hence, an investigation of the charge states of fluorinated balanol analogues will yield highly valuable information in order to assess which of these charge states act as the major contributing species for kinase binding at biological assay pH (7.40) [13]. Similar to the earlier charge state investigation of balanol [19], we calculated the $\mathrm{p} K_{\mathrm{a}}$ value [20] for each functional group of the balanol analogues, in order to identify specific charge states relevant to binding. Each analogue, with its respective charge state bound to either PKA or PKCE, was subjected<smiles>O=C(N[C@H]1CNCCCC1OC(=O)c1cc(O)c(C(=O)c2c(O)cccc2O)c(O)c1)c1ccc(O)cc1</smiles>

(-)-balanol, 1<smiles>O=C(N[C@H]1CNCC(F)CC1OC(=O)c1cc(O)c(C(=O)c2c(O)cccc2O)c(O)c1)c1ccc(O)cc1</smiles>

(6S)-F analogue, 1a<smiles>O=C(N[C@H]1CNCC[C@@H](F)C1OC(=O)c1cc(O)c(C(=O)c2c(O)cccc2O)c(O)c1)c1ccc(O)cc1</smiles>

(5S)-F analogue, 1c<smiles></smiles>

$(6 R, S)$-diF analogue, $1 d$<smiles>O=C(N[C@@H]1CNCC(F)(F)[C@H](F)C1OC(=O)c1cc(O)c(C(=O)c2c(O)cccc2O)c(O)c1)c1ccc(O)cc1</smiles>

(5S)-(6R,S)-trif analogue, $1 \mathrm{e}$

Fig. 2 Balanol and its fluorinated analgues $\mathbf{1 a}, \mathbf{1} \mathbf{c}, \mathbf{1} \mathbf{d}$ and $\mathbf{1 e}$. Fluorine substitutions in the analogues are in the azepane ring, in positions 5 and/ or 6 (as labelled in Fig. 1) 
to an MD simulation (as detailed in the Methods section). Subsequently, binding energy values for each protein-ligand pair were determined using a Molecular Mechanics Generalized Born Surface Area (MMGBSA) approach (described in Methods). The results show that the fluorine substituent(s) and the local environment of the ATP site together determine the charge states of bound fluorinated balanol analogues under biological assay $\mathrm{pH}$. In the ATP site of $\mathrm{PKC} \varepsilon$, balanol 1 and the most promising fluorinated analogue 1c have charges on $\mathrm{N} 1, \mathrm{C} 6{ }^{\prime} \mathrm{OH}$, and $\mathrm{C} 15^{\prime}{ }^{\prime} \mathrm{O}_{2} \mathrm{H}$, whereas $1 \mathrm{~d}$ and $1 \mathrm{e}$ bear charges only on $\mathrm{C6}^{\prime \prime} \mathrm{OH}$ and $\mathrm{C} 15^{\prime \prime} \mathrm{O}_{2} \mathrm{H}$. These balanol analogues also retain their charge states when they are bound to PKA. In contrast, analogue 1a, which is fluorinated on C6(S), exhibits different charge states in the ATP sites of PKA and PKCE. Specifically, $\mathrm{N} 1$ and $\mathrm{C6}^{\prime \prime} \mathrm{OH}$ of $1 \mathrm{a}$ are neutral in PKA, whereas PKC $\varepsilon$-bound 1a may exist as two species: one bearing ionised $\mathrm{N} 1$ and $\mathrm{C6}^{\prime \prime} \mathrm{OH}$ and the other possessing both functional groups in the uncharged state. The information obtained from this study will be beneficial for further rational design of balanol analogues to improve binding affinity for $\mathrm{PKC} \varepsilon$, as well as improved $\mathrm{PKC}$ isozyme selectivity.

\section{Methods}

\section{Initial $\mathrm{p} K_{\mathrm{a}}$ assignment}

$\mathrm{p} K_{\mathrm{a}}$ values of basic and acidic functional groups present in all analogues were estimated using Marvin Suite 17.1.30.0 [20, 21], at physiological $\mathrm{pH}$ (7.4). The predicted $\mathrm{p} K_{\mathrm{a}}$ values were used as the starting point for assigning charge to the basic and acidic groups.

\section{Homology modelling}

The catalytic domain of human PKA (UniProt ID: P17612) and PKCe (UniProt ID: Q02156) binding balanol were prepared using a homology modelling approach as reported previously [13]. We used a crystal structure of mouse PKA-balanol (PDB ID: 1BX6) [3] as the template for homology modelling of human PKA. For human $\mathrm{PKC} \varepsilon$, the homology model was built based on two crystal structure templates: from mouse PKA and human PKC $\eta$ (PDB ID: 3TXO). The templates were structurally aligned using the jCE algorithm [22] to examine the equivalency of both structures. Subsequently, the sequence of human PKC $\varepsilon$ was aligned to 1BX6 and 3TXO sequences using CLUSTALX 2.1 [23]. In addition, we manually edited the sequence alignment to map the 'open' conformation [24] at the Gly-rich loop (GXGXXG) from 1BX6 to the PKCE model. The sequence homology and identity of human PKA and PKC $\varepsilon$ to the template sequences were calculated using EMBOSS Needle [25].

The homology modelling was performed in the presence of balanol, from mouse PKA-balanol (PDB ID: 1BX6) to retain the three dimensional $(3 \mathrm{D})$ characteristics of the ATP binding site of the resulting homology model. The
3D models of the protein kinases with bound balanol was built using MODELLER 9.14 [26]. The resulting models were ranked using the Discrete Optimised Protein Energy (DOPE) score [27]. The score represents the quality of the model and the lower the score, the more native-like the corresponding model. Additionally, we overlaid models from several Modeller runs and selected the model which has residues adopting consensus conformations. The model was further assessed using the Ramachandran plot from the PROCHECK webserver [28]. Molecular surface electrostatic potentials (MSEPs) of PKA and PKC $\varepsilon$ were calculated using Adaptive Poisson-Boltzmann Solver (APBS) Version 0.5.1 [29] as implemented in AutoDockTools Version 1.5.6 [30].

\section{Molecular dynamics simulation preparation and protocol}

Fully activated human PKA and PKCe have phosphorylated residues at several specific sites [31]. Thus, we added a phosphoryl moiety on PKA to each of the phosphorylated residues: Thr198 and Ser339 using Discovery Studio Visualizer [32]. Likewise, phosphoryl moieties were also appended on Thr566, Thr710, and Ser729 of PKCE. The initial poses of bound balanol and its fluorinated analogues were adopted from the conformation of the ligand in 1BX6, where mouse PKA was co-crystallised with balanol.

Atomic charges and force-field parameters are needed to describe interatomic interactions in MD simulations. For balanol and its analogues in various protonation states, their atomic charges were calculated using the Austin model 1 - bond charge corrections (AM1-BCC) [33] procedure using Amber tools [34]. Their parameters were assigned from the General Amber Force-fields (GAFF) [35] and those missing in GAFF were determined using the parmchk program in Amber tools. Proteins and their side chains were assigned Amber ff14SB [36] force-field parameters, whereas phosphorylated amino acids used phosaa10 [37] parameters.

Before MD simulation, each complex of either PKA- or PKC $\varepsilon$-balanol-analogue was solvated in an explicit TIP3P water model using the LEaP module in Amber tools. The minimum buffering distance between the protein and box boundary was set to $10 \AA$. A number of $\mathrm{Na}^{+}$and $\mathrm{Cl}^{-}$ions were then added to obtain neutral charge and a concentration of $0.15 \mathrm{M}$, which is the equivalent of salt concentration under physiological conditions.

The MD simulation protocol was adapted from Homeyer and Gohlke [38]. For each simulation, an energy minimisation with high restraint $\left(25 \mathrm{kcal}_{\mathrm{mol}} \mathrm{m}^{-1} \AA^{-2}\right)$ to the solute was performed, followed by one with low restraint (5 kcal.mol ${ }^{-1} \AA^{-2}$ ). After minimisation, the system temperature was increased to $300 \mathrm{~K}$ under NVT condition over 50 ps, followed by equilibration 
as described in next sentences. In the next 50 ps of NPT simulation, the system density was adjusted to 1 g. $\mathrm{cm}^{-1}$. Subsequently, restraint on solute was gradually decreased by $1 \mathrm{kcal} \mathrm{mol}^{-1} \AA^{-2}$ every 50 ps over the rest of the NVT simulation, with the last 50 ps simulation carried out without restraint.

Production-phase simulations of 100 ns were conducted at $300 \mathrm{~K}$ under the NPT ensemble conditions for all systems, where the periodical boundary conditions were applied. During simulation, long-range electrostatic interactions were treated by particle-mesh Ewald (PME) method. For short-range non-bonded interactions, we employed a $10 \AA$ cut-off which was also implemented previously by Fisette et al. [39] and Kumar et al. [40]. All bonds involving hydrogen atoms were constrained by using the SHAKE algorithm [41]. Algorithms of Berendsen barostat [42] and Langevin thermostat [43] were used to maintain constant pressure and temperature, respectively. All production-phase simulations were run using GPU accelerated particle-mesh Ewald molecular dynamics (PMEMD) as implemented in Amber16 [34].

\section{Binding energy calculation}

Experimental binding energy or binding affinity values between balanol analogues and PKA or PKCe were derived from the dissociation constant $\left(K_{\mathrm{d}}\right)$ values as presented in Table 1 [13]. At equilibrium and under standard conditions, the binding energy is related directly to the equilibrium constants and, thus, can be calculated using formulae as follows:

$$
\Delta G_{\text {experiment }}^{\circ}=-R T \ln \left(K_{a}\right)=R \ln \left(K_{d}\right)
$$

where $\Delta G_{\text {experiment }}^{\circ}$ is the experimental binding energy, $K_{\mathrm{a}}$ and $K_{\mathrm{d}}$ are the association and dissociation constants, respectively, $\mathrm{R}$ is the universal gas constant, and $\mathrm{T}$ is the absolute temperature.

Calculated binding energy values between balanol analogues and PKA or PKCE were estimated using Molecular Mechanics Generalised Born Surface Area (MMGBSA) approach [44] as implemented in MMPBSA.py [45]. The MMGBSA binding free energy $\left(\triangle G_{M M G B S A}^{\circ}\right)$ is calculated by:

$$
\Delta G_{M M G B S A}^{\circ}=\left\langle G_{\text {complex }}\right\rangle_{i}-\left\langle G_{\text {enzyme }}\right\rangle_{i}-\left\langle G_{\text {ligand }}\right\rangle_{i}
$$

Here $\left\langle G_{x}\right\rangle_{i}$, with $x$ is complex, enzyme, or ligand, denotes the average value of the MMGBSA free energy for complex, enzyme, or ligand over snapshots $i$ obtained from MD trajectories. $G_{x}$ can be broken down into three components:

$$
G_{x}=E_{M M}+G_{\text {solv }}^{G B}+G_{\text {solv }}^{S A}
$$

where $E_{M M}$ is the gas phase energy, $G_{\text {solv }}^{G B}$ the electrostatic portion of solvation energy determined using
Generalised Born (GB) implicit solvent model, and $G_{\text {solv }}^{S A}$ the hydrophobic contribution to the solvation energy. The hydrophobic contribution is approximated by the Linear Combination of Pairwise Overlaps (LCPO) method [46]. $E_{M M}$ is estimated by the molecular mechanics energy of the molecule consisting bond, angle, and torsion energies as well as van der Waals and electrostatic interaction which can be expressed as:

$$
\begin{aligned}
E_{M M} & =\sum_{\substack{\text { bonds } \\
\text { atoms }}} E_{\text {bond }}+\sum_{\substack{\text { angles } \\
\text { atoms }}} E_{\text {angle }}+\sum_{\text {torsions }} E_{\text {torsion }} \\
& +\sum_{i \neq j} E_{v d W}+\sum_{i \neq j} E_{\text {electrostatic }}
\end{aligned}
$$

$E_{\text {bond }}, E_{\text {angle }}$, and $E_{\text {torsion }}$ terms were eliminated in the computation, since only protein-ligand complexes were subjected to MD simulations (single trajectory) [18]. $\triangle G_{M M G B S A}^{\circ}$ for each balanol analogue bound to PKA or PKCe was calculated within a 10-ns-sliding window every $10 \mathrm{~ns}, 100$ snapshots per sliding window. Plots of $\triangle G_{M M G B S A}^{\circ}$ values and their correlation coefficient with experimental binding energy were visualised using a ggplot2 package [47] in $\mathrm{R}$ statistical software [48].

\section{Results}

The effect of fluorine incorporation on acidity and basicity of functional groups on balanol analogues

As depicted in Fig. 1 and Table 2, balanol has polar protic functional groups comprising one basic and five acidic groups. The basic functional group is a secondary amine (N1) on the azepane moiety (ring B). The acidic ones consist of a carboxylic acid $\left(\mathrm{C}^{1} 5^{\prime}{ }^{\prime} \mathrm{O}_{2} \mathrm{H}\right)$ on ring D of benzophenone and four phenolic groups: one $\left(\mathrm{C}^{\prime} \mathrm{OH}\right)$ on the benzamide moiety; two $\left(\mathrm{C}^{\prime}{ }^{\prime \prime} \mathrm{OH}\right.$ and $\left.\mathrm{C}^{\prime \prime} \mathrm{OH}\right)$ on ring $\mathrm{C}$ and one $\left(\mathrm{C}^{\prime} 0^{\prime \prime} \mathrm{OH}\right)$ on ring $\mathrm{D}$ of benzophenone.

To get a preliminary estimate before performing charge state exploration on balanol and its fluorinated analogues (shown in Fig. 2), we calculated $\mathrm{p} K_{\mathrm{a}}$ values of these polar protic functional groups (Table 2) using Marvin [20, 21].

Table 2 Predicted $p K_{a}$ values of the ionisable functional groups on (-)-balanol and its analogues

\begin{tabular}{lllllll}
\hline Analogue & \multicolumn{6}{l}{ Marvin estimates of $\mathrm{pK}_{\mathrm{a}}$} \\
\cline { 2 - 7 } & $\mathrm{N} 1$ & $\mathrm{C} 5^{\prime} \mathrm{OH}$ & $\mathrm{C} 4{ }^{\prime \prime} \mathrm{OH}$ & $\mathrm{C6}{ }^{\prime} \mathrm{OH}$ & $\mathrm{C10} 0^{\prime} \mathrm{OH}$ & $\mathrm{C15}^{\prime \prime} \mathrm{O}_{2} \mathrm{H}$ \\
\hline $\mathbf{1}$ & 9.65 & 8.58 & 7.94 & 6.52 & 7.22 & 2.98 \\
$\mathbf{1 a}$ & 8.22 & 8.74 & 7.77 & 6.51 & 7.18 & 2.98 \\
$\mathbf{1 c}$ & 9.37 & 8.55 & 7.93 & 6.52 & 7.22 & 2.98 \\
$\mathbf{1 d}$ & 6.20 & 8.62 & 7.96 & 6.73 & 7.28 & 2.98 \\
$\mathbf{1 e}$ & 6.20 & 8.62 & 7.96 & 6.73 & 7.28 & 2.98 \\
\hline
\end{tabular}


Marvin predicts $\mathrm{p} K_{\mathrm{a}}$ values mainly based on calculated empirical partial charges and parameterized hydrogen bonds, and has also been utilized by Drugbank [49] for $\mathrm{p} K_{\mathrm{a}}$ prediction. For the natural balanol (labelled $\mathbf{1}$ in Fig. 2), Marvin predicted that the amine N1 on the azepane ring has a $\mathrm{p} K_{\mathrm{a}}$ value of 9.65 and the phenolic $\mathrm{C}^{\prime} \mathrm{OH}$ on the benzamide moiety has a $\mathrm{p} K_{\mathrm{a}}$ value of 8.58 . On the benzophenone moiety, the predicted $\mathrm{p} K_{\mathrm{a}}$ value for the carboxyl $\mathrm{C}^{\prime} 5^{\prime \prime} \mathrm{O}_{2} \mathrm{H}$ is 2.98. The phenolic $\mathrm{C} 4 .{ }^{\prime \prime} \mathrm{OH}$ and $\mathrm{C6}^{\prime \prime} \mathrm{OH}$ on the ring $\mathrm{C}$ have $\mathrm{p} K_{\mathrm{a}}$ values of 7.94 and 6.52, respectively, whereas that of $\mathrm{C} 10^{\prime \prime} \mathrm{OH}$ on the $\mathrm{D}$ ring is 7.22. Hence, the natural balanol $\mathbf{1}$ has a positive charge on $\mathrm{N} 1$ and negative charges only on $\mathrm{C}^{\prime}{ }^{\prime} \mathrm{OH}$ and $\mathrm{C}^{\prime} 5^{\prime}{ }^{\prime} \mathrm{O}_{2} \mathrm{H}$ at biological assay $\mathrm{pH}$ (7.40). According to Marvin, the introduction of fluorine on the azepane ring, as seen in all of the fluorinated balanol analogues, affects only very slightly the $\mathrm{p} K_{\mathrm{a}}$ of $\mathrm{C}^{\prime} \mathrm{OH}$ on the benzamide moiety. The predicted $\mathrm{p} K_{\mathrm{a}}$ values of the benzamide phenolic moiety for all analogues are above 8.00, suggesting that this moiety is uncharged at biological assay $\mathrm{pH}$ (7.40). Uncharged benzamide may benefit the binding of balanol analogues to kinases, particularly in the adenine subsite. The adenine subsites of both PKA and PKC are dominated by hydrophobic residues that favour uncharged moieties or ligands.

On the azepane ring itself, the introduction of fluorine influences the basicity of the amine group (N1). The presence of a highly electronegative fluorine atom on C6 $(S)$ (analogue 1a) decreases the basicity of the N1, as indicated by its predicted $\mathrm{p} K_{\mathrm{a}}$ (8.22) [50]. This electron withdrawing effect is less pronounced for $1 \mathrm{c}$ where the fluorine atom (on $\mathrm{C} 5(S)$ ) is further away from N1. As shown by Marvin prediction, $\mathrm{p} K_{\mathrm{a}}$ of $\mathrm{N} 1$ on $\mathbf{1 c}$ is only slightly decreased to 9.37. Meanwhile, di- and trifluorination on $\mathrm{C} 6(R, S)(\mathbf{1 d})$ and $\mathrm{C} 5(S)-\mathrm{C} 6(R, S)(\mathbf{1 e})$, respectively, are predicted to dramatically lower the basicity of the N1 as shown in Table 2. Based on these predicted $\mathrm{p} K_{\mathrm{a}}$ values, the $\mathrm{N} 1$ groups on $\mathbf{1}, \mathbf{1 a}$, and $\mathbf{1 c}$ are expected to be protonated and have a positive charge at biological assay $\mathrm{pH}$ (7.40), whereas the N1 groups on $\mathbf{1 d}$ and $\mathbf{1 e}$ are unprotonated (uncharged).

Predicted $\mathrm{p} K_{\mathrm{a}}$ values suggest that the presence of fluorine on the azepene ring slightly alters the acidity of polar protic functional groups on the benzophenone moiety. These acidity alterations do not affect the charge states of functional groups on the benzophenone moiety. Marvin predicts that the all balanol analogues have negative charges on $\mathrm{C}^{\prime \prime} \mathrm{OH}$ and $\mathrm{C} 15^{\prime}{ }^{\prime} \mathrm{O}_{2} \mathrm{H}$, while $\mathrm{C} 4{ }^{\prime}{ }^{\prime} \mathrm{OH}$ and $\mathrm{C} 10^{\prime} \mathrm{OH}$ are neutral at the biological assay $\mathrm{pH}$ (7.40).

Wong et al. [19] reported only a negative charge on the benzophenone carboxylate $\left(\mathrm{C} 15^{\prime \prime} \mathrm{O}_{2} \mathrm{H}\right)$ and a positive charge on the amine (N1) azepane of balanol, when bound to the ATP site of PKA. Marvin results additionally suggest a negative charge on $\mathrm{C}^{\prime \prime}{ }^{\prime} \mathrm{OH}$.

\section{Charge state exploration of balanol and its fluorinated analogues in the ATP site of PKA}

We first assigned the charge state for balanol analogues as reported previously [19], keeping the phenolic groups uncharged. The charge on $\mathrm{C}^{1} 5^{\prime \prime} \mathrm{O}_{2} \mathrm{H}$ and $\mathrm{N} 1$ are known to be useful for binding of balanol to the ATP site of PKA. Thus, we assigned $\mathrm{C} 15^{\prime \prime} \mathrm{O}_{2}^{-}$and $\mathrm{N}_{1} \mathrm{H}_{2}^{+}$for $\mathbf{1}, \mathbf{1 a}$, and 1c (Table 3, column B). For 1d and 1e (Table 3, column B), their amine groups (N1) were kept uncharged since their predicted $\mathrm{p} K_{\mathrm{a}}$ values (Table 2) are well below the $\mathrm{pH}$ of biological assays (7.40). All these analogues with respective charge states were labelled as a charge state combination I (Table 4). The balanol moiety in the PKA model was then replaced with the analogue in the correct charge state, neutralized with counter ions $\left(\mathrm{Na}^{+}\right.$or $\left.\mathrm{Cl}^{-}\right)$, and solvated by explicit TIP3P water model. Additional $\mathrm{Na}^{+}$or $\mathrm{Cl}^{-}$ions were also added to reach the physiological salt concentration of $0.15 \mathrm{M}$. Every solvated complex of PKA-bound balanol analogue was subsequently subjected to MD simulation to yield a trajectory of $100 \mathrm{~ns}$. From each trajectory of PKA-bound balanol analogues, binding energy values were calculated within a 10-ns sliding window every 10 ns using MMGBSA approach.

$\triangle G_{M M G B S A}^{\circ}$ profiles of PKA-bound balanol analogues (Additional file 1: Figure S1) show that the calculated binding energy values do not corroborate well with experiment results (Table 1). The experimental binding affinity values in Table 1 suggest that $\mathbf{1}, \mathbf{1 a}, \mathbf{1 c}$, and $\mathbf{1 d}$ bind to PKA with comparable affinities, whereas 1e is a significantly weaker binding partner. Similarity in calculated $\triangle G_{M M G B S A}^{\circ}$ values, however, is observed for $\mathbf{1 a}$ and $\mathbf{1 e}$, but not for 1, 1a, 1c, and 1d (Additional file 1: Figure S1). In addition, a good correlation coefficient $\left(r^{2}\right)$ between the experimental and calculated binding energy only appears once in the first 10-ns of trajectory, after which the $r^{2}$ values fall to below 0.50 until the end of the simulation. Clearly, we need to explore charge states other than those reported by Wong et al. [19].

Table 3 Charge states of balanol analogues

\begin{tabular}{|c|c|c|c|c|}
\hline \multirow[t]{3}{*}{ Analogue } & \multicolumn{4}{|c|}{ Charge state selected, indicated by $\mathrm{x}$} \\
\hline & A & B & C & $\mathrm{D}$ \\
\hline & $\begin{array}{l}\mathrm{COO}^{-} ; \mathrm{NH} \\
\mathrm{OH}\end{array}$ & $\begin{array}{l}\mathrm{COO}^{-} ; \mathrm{NH}_{2 i}^{+} \\
\mathrm{OH}\end{array}$ & $\begin{array}{l}\mathrm{COO}^{-} ; \mathrm{NH}_{2}^{+} ; \\
\mathrm{O}^{-}\end{array}$ & $\begin{array}{l}\mathrm{COO}^{-} ; \mathrm{NH} ; \\
\mathrm{O}^{-}\end{array}$ \\
\hline 1 & & $\times$ & $x$ & \\
\hline $1 \mathrm{a}$ & $x$ & $x$ & $x$ & \\
\hline $1 c$ & & $\times$ & $x$ & \\
\hline $1 d$ & $x$ & & & $\times$ \\
\hline 1e & $x$ & & & $x$ \\
\hline
\end{tabular}


Table 4 Combination of charge states

\begin{tabular}{llll}
\hline Analogue & \multicolumn{2}{l}{ Charge state $^{a}$ combination } \\
\cline { 2 - 4 } & I & II & III \\
\hline $\mathbf{1}$ & $\mathrm{B}$ & $\mathrm{C}$ & $\mathrm{C}$ \\
$\mathbf{1 a}$ & $\mathrm{B}$ & $\mathrm{C}$ & $\mathrm{A}$ \\
$\mathbf{1 c}$ & $\mathrm{B}$ & $\mathrm{C}$ & $\mathrm{C}$ \\
$\mathbf{1 d}$ & $\mathrm{A}$ & $\mathrm{D}$ & $\mathrm{D}$ \\
$\mathbf{1 e}$ & $\mathrm{A}$ & $\mathrm{D}$ & $\mathrm{D}$ \\
\hline
\end{tabular}

${ }^{\mathrm{a}} \mathrm{A}, \mathrm{B}, \mathrm{C}$ and $\mathrm{D}$ as defined in Table 3

According to the Marvin prediction (Table 2), the phenolic group at C6" among all analogues has $\mathrm{p} K_{\mathrm{a}}$ values ranging from 6.50 to 6.75 . Thus, at the $\mathrm{pH}$ of biological assays (7.40), this functional group is most likely to bear a negative charge. The phenolate group $\left(\mathrm{C}^{\prime \prime} \mathrm{O}^{-}\right)$was then assigned for 1, 1a, 1c (Table 3, column $C$ ), and for 1d, and 1e (Table 3, column D) and grouped as charge state combination II (Table 4). All analogues, in the PKA-bound state, were then subjected to MD simulations to yield trajectories of $100 \mathrm{~ns}$. Extracted from MD trajectories, the $r^{2}$ profile shows that $\triangle G_{M M G B S A}^{\circ}$ values of all PKCe-bound analogues still show poor correlation with experimental data (Additional file 2: Figure S2B). Most of the $r^{2}$ values are around 0.10 .

From the $\triangle G_{M M G B S A}^{\circ}$ profile of PKA-bound balanol analogues in the charge state combination II (Table 4), we noticed that the calculated binding energy of $\mathbf{1 a}$ is an outlier (Additional file 2: Figure S2A). In analogue 1a, the fluorine atom is on $\mathrm{C} 6(S)$ which is in the $\beta$-position from N1 that has a $\mathrm{p} K_{a}$ value of 8.22 . Given that Marvin has a root-mean-squared (RMS) error of about $1 \mathrm{p} K_{a}$ unit [21], this value is in the range 7.22-9.22, making this amine either uncharged or positively charged at $\mathrm{pH}$ 7.4. Hence, we explored another charge state for 1a in which $\mathrm{N} 1$ is neutral. The $\mathrm{C}^{\prime \prime}{ }^{\prime} \mathrm{OH}$ was also treated as uncharged for 1a as reported before [19]. We grouped this new charge of $\mathbf{1 a}$ in combination III with the remaining analogues retaining their charge states in combination II (Table 3). Subsequently, we run another set of $\mathrm{MD}$ simulations. The result show that the $\triangle G_{M M G B S A}^{\circ}$ profile of 1a (Fig. 3a) moves closer to that $\mathbf{1}$, 1c, and 1d. As expected, $r^{2}$ profiles for PKA-bound analogues were improved when we use charge state combination III (Fig. 3b). This combination has average $r^{2}$ of 0.72 , calculated from a trajectory between 40 and 100 ns. These explorations suggest that balanol analogues most likely have charge states as listed in combination III when bound to the ATP site of PKA.

\section{Charge state exploration of balanol and its fluorinated analogues in the ATP site of PKC $\varepsilon$}

In the charge state exploration of balanol analogues in the ATP site of PKCE, we used the same approach as described above for PKA (Table 4). Using charge state combination I, however, resulted in $\triangle G_{M M G B S A}^{\circ}$ profiles for PKC $\varepsilon$-bound balanol analogues (Additional file 3: Figure S3A) that disagree with the experimental results, where the order of binding affinity is 1c $>\mathbf{1}>>\mathbf{1 a}>\mathbf{1 e}>>\mathbf{1 d}$. The analogues having the strongest experimental binding affinity for $\mathrm{PKC} \varepsilon, \mathbf{1}$ and 1c, also have the lowest calculated binding energy values for charge state I. Moreover, throughout the trajectory, all $r^{2}$ values are below 0.50 (Additional file 3: Figure S3B).

Combination II gave $\triangle G_{M M G B S A}^{\circ}$ profiles that follow the experiment result, where $\mathbf{1 c}$ and $\mathbf{1 d}$ are the strongest and weakest ligands, respectively, among other analogues (Fig. 4a combination II). The $r^{2}$ profile also exhibits good correlations between $\triangle G_{M M G B S A}^{\circ}$ and experimental binding energy values (Fig. 4b combination II). Average $r^{2}$ for combination II is 0.73 , which was calculated between 40 and 100 ns of trajectory.

Interestingly, charge state combination III yielded a similar $\triangle G_{M M G B S A}^{\circ}$ profile to that using combination II (Fig. 4a combination III). Furthermore, the $r^{2}$ profile shows slightly improved correlations (Fig. 4b combination III) with average of 0.78 .

These results suggests that PKA-bound balanol analogues most likely possess the same charge states to those bound to PKCe, except for 1a. Balanol 1 and the most promising fluorinated analogue (1c) bear charges on the azepane amine, $\mathrm{N} 1$ and on the phenol $\mathrm{C}^{\prime}{ }^{\prime} \mathrm{OH}$ and the carboxyl $\mathrm{C} 5^{\prime} \mathrm{O}_{2} \mathrm{H}$, of the benzophenone moiety. Analogues $1 \mathbf{d}$ and 1e retain the carboxylate and phenol group charges while the amine group remains uncharged. While PKA-bound 1a has uncharged N1 and C6" 'OH, 1a may adopt two charge states when it is bound to the ATP site of PKCE, with $\mathrm{N} 1$ being either charged or neutral.

\section{Discussion}

The influence of fluorine substituent and local environment of ATP site on charge state of balanol analogues

Fluorine is a highly electronegative substituent with very little steric effect on the the balanol molecule $[14,15]$. The inductive effect of fluorine substitution on the azepane ring alters the acidity and basicity of polar protic functional groups in the balanol system. This in turn influences the charge states of balanol analogues and consequently their binding to the ATP site of protein kinases such as PKA and PKCE. We find that fluorination can significantly affect the charge state of $\mathrm{N} 1$ at bioassay $\mathrm{pH}$ (7.40). For analogue 1a, monofluorination on the carbon $\beta$ to $\mathrm{N} 1$ can reduce the basicity of the amine group to leave it unprotonated at the bioassay $\mathrm{pH}$. Installation of a single fluorine on the carbon $\gamma$ to N1 (1c) also reduces the basicity of N1, but it does not change the charge state at the bioassay $\mathrm{pH}$. A more pronounced effect of charge state alteration is found by our calculation when di- or trifluorination is introduced on the azepane ring. 

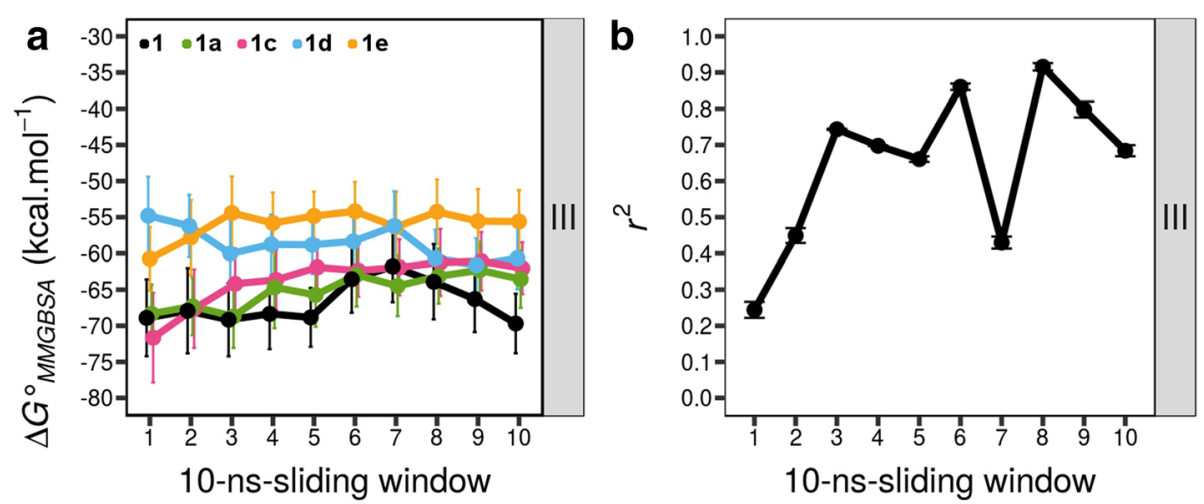

Fig. 3 a Trajectory of $\triangle G_{M M G B S A}^{\circ}$ of PKA-bound balanol analogues in charge state combination III and $\mathbf{b}$ the correlation coefficients to experimental binding energy over $100 \mathrm{~ns}$ of MD simulations. Each data point in a was obtained from a 10-ns sliding window every $10 \mathrm{~ns}$. Error bars in a were obtained from $\triangle G_{\text {MMGBSA }}^{\circ}$ calculations of 100 snapshots within $10 \mathrm{~ns}$ trajectory. Error bars in $\mathbf{b}$ were derived from the errors of experimental $K_{d}$ values

Our MD simulations suggest that PKA-bound balanol analogues in charge state combination III gives $\Delta G_{M M G B S A}^{\circ}$ values well correlated with experiment results. In this combination list, 1a has an uncharged N1. Meanwhile, for balanol analogues bound to the ATP site of PKCE, good agreements between simulated $\triangle G_{M M G B S A}^{\circ}$ values and experiment results are observed for charge state combination II and III. These results suggest that 1a possesses $\mathrm{N} 1$ either in an uncharge or charge state when it is bound to the ATP site of PKC $\varepsilon$. The charge states of balanol in the bound form may also be influenced by the local environment of each subsite in the ATP site. The ribose subsite in PKA where azepane resides has a molecular surface electrostatic potential (MSEP) that is close to neutral (Fig. 5a indicated by $\mathrm{X}$ ). This may retain the N1 of azepane ring uncharged. For PKCE, its MSEP at the ribose subsite indicates a slight negative or acidic environment (Fig. 5b indicated by $\mathrm{X}$ ) which allows $1 \mathrm{a}$ to be protonated at N1, whereas the others
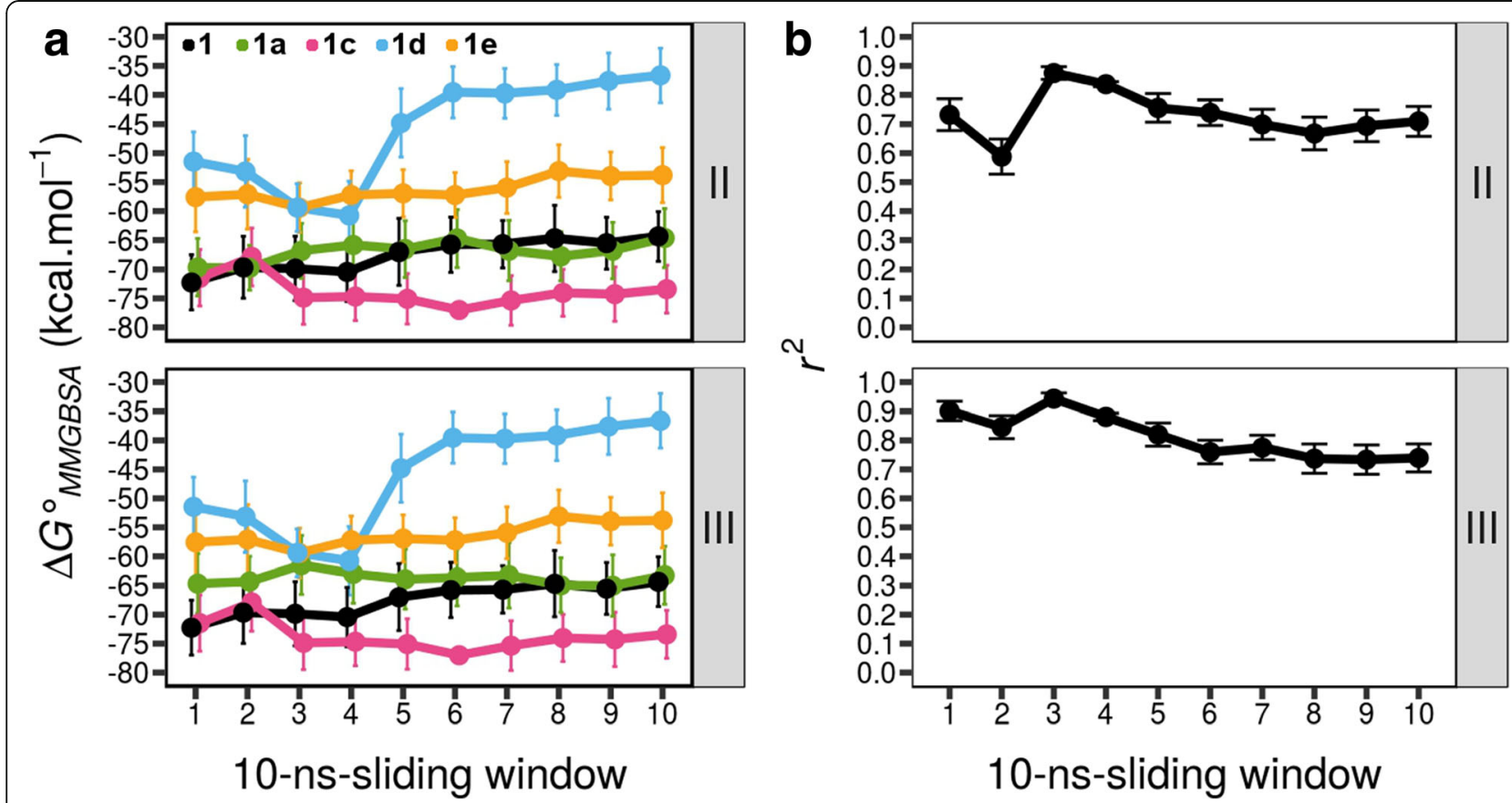

Fig. 4 a Trajectory of $\triangle G_{M M G B S A}^{\circ}$ of PKCE-bound balanol analogues in charge state combinations II and III and $\mathbf{b}$ the respective correlation coefficients to experimental binding energy over 100 ns of MD simulations. Row labels (II, and III) indicate charge state combinations. Each data point in a was obtained from a 10-ns sliding window every $10 \mathrm{~ns}$. Error bars in a were obtained from $\triangle G_{M M G B S}^{\circ}$ calculations of 100 snapshots within 10 ns trajectory. Error bars in $\mathbf{b}$ were derived from the errors of experimental $K_{d}$ values 


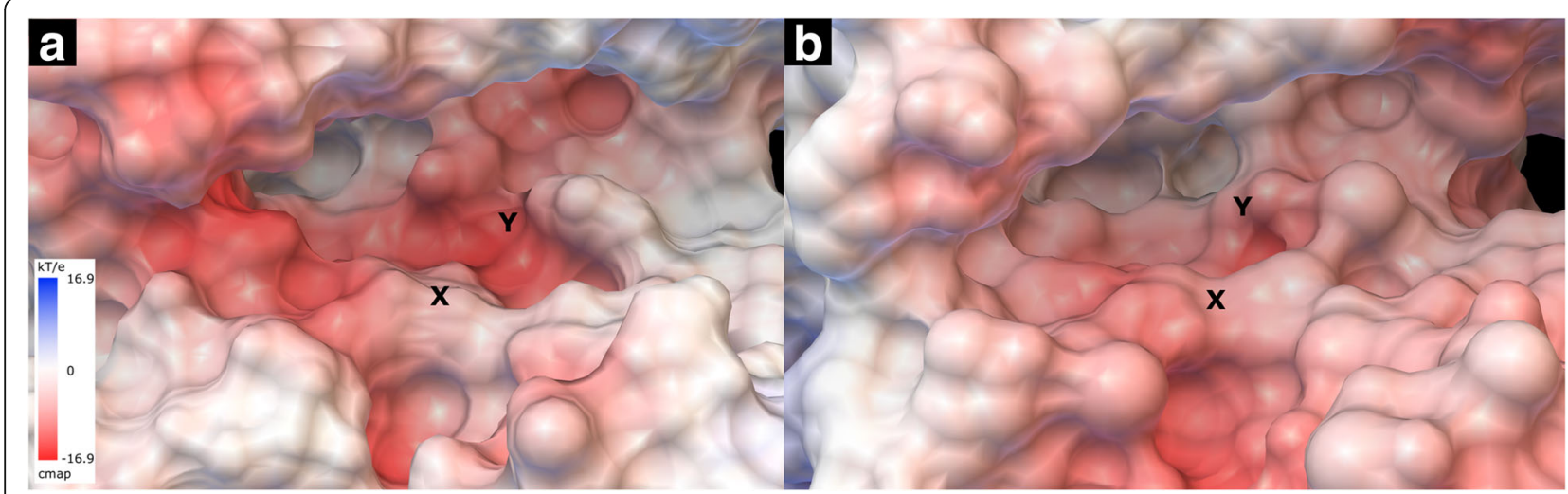

Fig. 5 Molecular surface electrostatic potential (MSEP) of ATP sites of a PKA and $\mathbf{b}$ PKC $\varepsilon$. X indicates the position of N1, whereas $\mathrm{Y}$ is the site for $\mathrm{C6} " \mathrm{OH}$

are uncharged or unprotonated at N1. This may in part explain why analogue 1a has comparable binding affinity to that of $\mathbf{1}$ in the PKA ATP pocket, as the protein active site is neutral and less sensitive to the charge state of the ligand at N1. For the ATP pocket of PKCe that is more acidic and negatively charged, the neutral charge state of $\mathrm{N} 1$ of 1a would cause significant loss in ionic interactions, which is consistent with the experimental observation that 1a is a significantly worse ligand compared to native balanol (1). A positive charge on $\mathrm{N} 1$ of the azepane ring may be an indicator for balanol analogues to strongly bind the ATP site of PKCe, as reflected by 1c, the best ligand among the analogues in this study.

In addition to $\mathrm{N} 1$, our charge state exploration also suggests that $\mathrm{C6}^{\prime \prime} \mathrm{OH}$ on 1a binds differently in the ATP site of PKA from that of PKCE. In the ATP site of PKA, the $\mathrm{C6}^{\prime \prime} \mathrm{OH}$ is in its uncharged state, whereas when 1a is bound to PKCe, it may exist in either the uncharged or the charged state. The nature of the triphosphate subsites between PKA and PKC $\varepsilon$ differ, which may influence the charge state of $\mathrm{C}^{\prime \prime}{ }^{\prime} \mathrm{OH}$ in the case of 1a. $\mathrm{PKC} \varepsilon$ possesses a less negative or less acidic MSEP triphosphate subsite (indicated by $\mathrm{Y}$ in Fig. 5) than PKA.

\section{Molecular dynamics binding of balanol analogues}

Balanol analogues exhibit dynamics $\triangle G_{M M G B S A}^{\circ}$ profiles over the MD simulation period (see Fig. 4a: charge combination III). The most striking feature is observed on the $\triangle G_{M M G B S A}^{\circ}$ profile of PKCE-bound $\mathbf{1 d}$ (in cyan line). The analogue 1d, as the weakest binder to $\mathrm{PKC} \varepsilon$, shows binding affinity increments for the first $40 \mathrm{~ns}$ of $\mathrm{MD}$ simulation to around $-60 \mathrm{kcal} . \mathrm{mol}^{-1}$, but its binding affinity dramatically decreases to $-40 \mathrm{kcal} \cdot \mathrm{mol}^{-1}$ afterwards and remains stable until the end of simulation. This may indicate that even though the binding affinity between 1d and the ATP site of PKCe initially increases, interactions of both ligand and receptor in the entropic term may be unfavorable for the whole $\mathrm{PKC} \varepsilon$ system. As a result, the binding affinity decreases or becomes more positive (Fig. 4a charge combination III of PKCe-bound 1d). This transient higher binding affinity can be misleading, if the binding affinity is not thoroughly simulated as a profile of time-sliding window.

An interesting event is also observed on the $\triangle G_{M M G B S A}^{\circ}$ profile of $\mathrm{PKC} \varepsilon$-bound 1c. Being the analogue with highest affinity to $\mathrm{PKC} \varepsilon$, the binding affinity of $\mathbf{1 c}$ decreases to $-68 \mathrm{kcal}^{\mathrm{mol}}{ }^{-1}$ for the first $20 \mathrm{~ns}$, but then dips to and remains stable at around $-75 \mathrm{kcal}^{\mathrm{mol}}{ }^{-1}$. This may suggest that, during the simulation, 1c can alter its conformation to adapt to the flexible ATP site of PKCe. This conformation change in the ATP site may incur an entropic cost that is paid off by enthalpic compensation through induced fit. Such entropy-enthalpy compensation seems to benefit the binding affinity of $\mathbf{1 c}$ to PKCe.

\section{The effect of ligand charge states on predicted binding energy values}

Through this study, we demonstrated the importance of assigning correct charge states to ligands in binding energy calculations, which also has been reported previously [18]. Improper charge state assignments to ligands lead to disagreements between calculated and experimental binding energy values. For instance, we observed such disagreements on binding energy values of charge state combination I for both PKA- and PKCe-bound balanol analogues (Additional file 1: Figure S1 and Additional file 3: Figure S3, respectively). Assigning this combination to both PKA- and PKCe-bound balanol analogues yields poor correlation coefficients between calculated and experimental binding energy values. The correlations for PKA-bound balanol analogues are improved when combination III is employed (Fig. 3), whereas for PKCe-bound balanol analogues, satisfactory correlations are obtained 
by assigning combinations II for all analogues excepting 1a, for which combination II or III is acceptable (Fig. 4).

Charge distributions of the two ATP sites, which are represented by MSEPs, can have different abilities to accommodate charge interactions of ligands. Meanwhile, fluorination allows charge state diversification of ligands. Altogether, the charge distribution of ATP sites and ligand fluorination could be utilized as a tool for conferring specificity constraints of ligands.

\section{Conclusions}

(-)-Balanol has several polar protic functional groups that include basic and acidic groups. These groups can have different charge states depending on the environmental $\mathrm{pH}$. Furthermore, the presence of fluorine atom in the azepane ring alters the acidity and basicity of functional groups in the balanol system. This alteration can change the charge states of major binding species of balanol analogues at biological assay $\mathrm{pH}$. In addition, the charge states of balanol analogues can be influenced by the local environment of the ATP site.

Here, we investigated charge states of novel fluorinated balanol analogues. This investigation suggests that PKCEbound balanol $\mathbf{1}$ and its fluorinated analogues 1c, 1d and 1e adopt the same charge states when bound to PKA, while 1a alone shows different charge states. For the first time and to the best our knowledge, we show that in addition to charges on $\mathrm{N} 1$ and $\mathrm{C} 15^{\prime}{ }^{\prime} \mathrm{O}_{2} \mathrm{H}$, a charged phenolate group $\left(\mathrm{C6}^{\prime \prime} \mathrm{O}^{-}\right)$is also important for the binding of balanol analogues in the ATP site of protein kinases. This is supported by the evaluation of MMGBSA binding energy values that correlate well with experimental data.

We also found that the charge state of the ligand can influence the calculated binding energy values, as previously observed $[18,19]$. Correct forms of charge states are important to generate reasonable binding energy from MD simulations. Ultimately, the insight from this study will help guide further rational designs of balanol analogues for improved selectivity of PKC isozymes and other related kinases.

\section{Additional files}

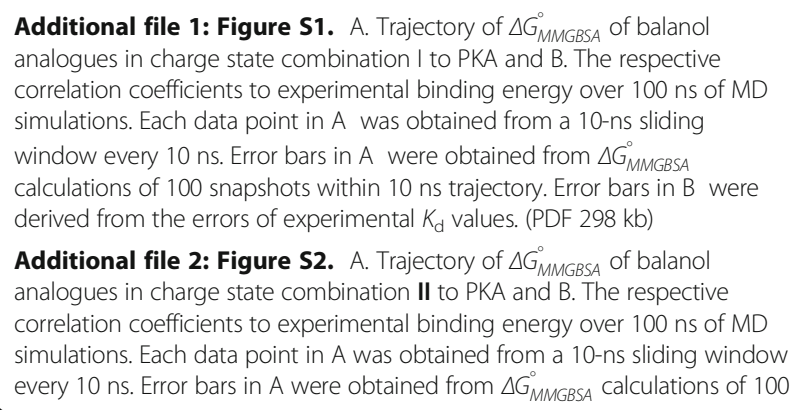

Additional file 2: Figure S2. A. Trajectory of $\triangle G_{M M G B S A}^{\circ}$ of balanol analogues in charge state combination II to PKA and $\mathrm{B}$. The respective correlation coefficients to experimental binding energy over $100 \mathrm{~ns}$ of MD simulations. Each data point in A was obtained from a 10-ns sliding window every $10 \mathrm{~ns}$. Error bars in $A$ were obtained from $\triangle G_{M M G B S A}^{\circ}$ calculations of 100

snapshots within 10 ns trajectory. Error bars in B were derived from the errors of experimental $K_{d}$ values. (PDF $255 \mathrm{~kb}$ )

Additional file 3: Figure S3. A. Trajectory of $\triangle G_{M M G B S A}^{\circ}$ of balanol analogues in charge state combination I to $\mathrm{PKC} \varepsilon$ and $\mathrm{B}$. the respective correlation coefficients to experimental binding energy over $100 \mathrm{~ns}$ of MD simulations. Each data point in A was obtained from a 10-ns sliding window every $10 \mathrm{~ns}$. Error bars in A were obtained from $\triangle G_{\text {MMGBSA }}^{\circ}$ calculations of 100 snapshots within $10 \mathrm{~ns}$ trajectory. Error bars in $\mathrm{B}$ were derived from the errors of experimental $K_{d}$ values. (PDF $258 \mathrm{~kb}$ )

\section{Abbreviations}

ATP: Adenosine triphosphate; Balanol: (-)-balanol; MD: Molecular dynamics; MMGBSA: Molecular Mechanics Generalized Born Surface Area; MSEP: Molecular surface electrostatic potential; PKA: Protein kinase A; PKC: Protein kinase C

\section{Acknowledgements}

We acknowledge the Indonesia Endowment Fund scholarship to AH and the National Computational Infrastructure (NCl), Australia for high-performance computer access. We are also thankful to ChemAxon for providing a free academic license of Marvin Suite 17.1.30.0. Values in Table 1 were adapted from Patel et al. [13].

\section{Funding}

Publication of this article was funded by Macquarie University.

\section{Availability of data and materials}

The MD simulation results are available from the authors on request.

\section{Authors' contributions}

$\mathrm{AH}$ carried out the computational simulation study and drafted the manuscript. MY assisted AH with MD simulation setup and with data analysis. AH, FL, and SR participated in the design of the study and interpretation of data. SR, FL and AH finalised the manuscript. All authors have read and approved the final manuscript.

\section{Ethics approval and consent to participate}

Not applicable.

\section{About this supplement}

This article has been published as part of BMC Bioinformatics Volume 18 Supplement 16, 2017: 16th International Conference on Bioinformatics (InCoB 2017): Bioinformatics. The full contents of the supplement are available online at https://bmcbioinformatics.biomedcentral.com/articles/ supplements/volume-18-supplement-16.

\section{Consent for publication}

Not applicable.

\section{Competing interests}

The authors declare that they have no competing interests.

\section{Publisher's Note}

Springer Nature remains neutral with regard to jurisdictional claims in published maps and institutional affiliations.

\section{Author details}

'Department of Molecular Sciences, Macquarie University, Sydney, NSW 2109, Australia. ${ }^{2}$ Department of Chemistry, Universitas Padjadjaran, Jatinangor, West Java 45363, Indonesia.

Published: 28 December 2017

\section{References}

1. Kulanthaivel P, Hallock YF, Boros C, Hamilton SM, Janzen WP, Ballas LM, Loomis CR, Jiang JB, Katz B. Balanol: a novel and potent inhibitor of protein kinase $C$ from the fungus Verticillium balanoides. J Am Chem Soc. 1993;115:6452-3. 
2. Taylor SS, Yang J, Wu J, Haste NM, Radzio-Andzelm E, Anand G. PKA: a portrait of protein kinase dynamics. Biochim Biophys Acta Proteins Proteomics. 2004;1697:259-69.

3. Narayana N, Diller TC, Koide K, Bunnage ME, Nicolaou KC, Brunton LL, Xuong N-H, Ten Eyck LF, Taylor SS. Crystal structure of the potent natural product inhibitor balanol in complex with the catalytic subunit of CAMP-dependent protein kinase. Biochemistry. 1999;38:2367-76.

4. Zheng J, Trafny EA, Knighton DR, Xuong N, Taylor SS, Ten Eyck LF, Sowadski JM. 2.2 a refined crystal structure of the catalytic subunit of CAMP-dependent protein kinase complexed with MnATP and a peptide inhibitor. Acta Crystallogr Sect D. 1993;49:362-5.

5. Koide K, Bunnage ME, Gomez Paloma L, Kanter JR, Taylor SS, Brunton LL, Nicolaou KC. Molecular design and biological activity of potent and selective protein kinase inhibitors related to balanol. Chem Biol. 1995;2:601-8.

6. Cho YS, Lee YN, Cho-Chung YS. Biochemical characterization of extracellular CAMP-dependent protein kinase as a tumor marker. Biochem Biophys Res Commun. 2000;278:679-84.

7. Garg R, Benedetti LG, Abera MB, Wang H, Abba M, Kazanietz MG. Protein kinase $C$ and cancer: what we know and what we do not. Oncogene. 2014; 33:5225-37.

8. Hu H, Mendoza JS, Lowden CT, Ballas LM, Janzen WP. Synthesis and protein kinase $C$ inhibitory activities of balanol analogues with modification of 4-hydroxybenzamido moiety. Bioorg Med Chem. 1997;5: 1873-82.

9. Lai YS, Mendoza JS, Jagdmann GE, Menaldino DS, Biggers CK, Heerding JM, Wilson JW, Hall SE, Jiang JB, Janzen WP, Ballas LM, Hu H, Mendoza JS, Lowden CT, Ballas LM, Janzen WP. Synthesis and protein kinase C inhibitory activities of balanol analogues with modification of 4-hydroxybenzamido moiety. Bioorg Med Chem. 1997;5:1873-82.

10. Crane HM, Menaldino DS, Erik Jagdmann G Jr, Darges JW, Buben JA Jagdmann GE, Darges JW, Buben JA. Increasing the cellular PKC inhibitory activity of balanol: a study of ester analogs. Bioorg Med Chem Lett. 1995;5: 2133-8

11. Heerding JM, Lampe JW, Darges JW, Stamper ML. Protein kinase C inhibitory activities of balanol analogs bearing carboxylic acid replacements. Bioorg Med Chem Lett. 1995:5:1839-42.

12. Lampe JW, Jagdmann GE, Johnson MG, Lai YS, Lowden CT, Lynch MP, Mendoza JS, Murphy MM, Wilson JW, Ballas LM, Carter K, Biggers CK, Darges JW, Davis JE, Hubbard FR, Stamper ML, Defauw JM, Foglesong RJ, Hall SE, Heerding JM, Hollinshead SP, Hu H, Hughes PF. Synthesis and protein kinase inhibitory activity of balanol analogues with modified benzophenone subunits. J Med Chem. 2002:45:2624-43.

13. Patel AR, Hardianto A, Ranganathan S, Liu F. Divergent response of homologous ATP sites to stereospecific ligand fluorination for selectivity enhancement. Org Biomol Chem. 2017:15:1570-4.

14. Hunter L. The C-F bond as a conformational tool in organic and biological chemistry. Beilstein J Org Chem. 2010;6:1-14.

15. O'Hagan D. Understanding organofluorine chemistry. An introduction to the C-F bond. Chem Soc Rev. 2008;37:308-19.

16. Mortier J, Rakers C, Bermudez M, Murgueitio MS, Riniker S, Wolber G. The impact of molecular dynamics on drug design: applications for the characterization of ligand-macromolecule complexes. Drug Discov Today. 2015;20:686-702

17. Hospital A, Goñi JR, Orozco M, Gelpi J. Molecular dynamics simulations: advances and applications. Adv Appl Bioinforma Chem. 2015;8:37-47.

18. Poongavanam V, Olsen JMH, Kongsted J. Binding free energy based structural dynamics analysis of HIV-1 RT RNase H-inhibitor complexes. Integr Biol. 2014;6:1010-22.

19. Wong CF, Kua J, Zhang Y, Straatsma TP, McCammon JA. Molecular docking of balanol to dynamics snapshots of protein kinase A. Proteins Struct Funct Genet. 2005;61:850-8.

20. ChemAxon (http://www.chemaxon.com): Marvin 17.1.30.0. 2017

21. Manchester J, Walkup G, Rivin O, You Z, Shelley JC, Calkins D, Sullivan AP. Evaluation of pKa estimation methods on 211 druglike compounds. J Chem Inf Model. 2010;50:565-71.

22. Prlic A, Bliven S, Rose PW, Bluhm WF, Bizon C, Godzik A, Bourne PE. Pre-calculated protein structure alignments at the RCSB PDB website. Bioinformatics. 2010;26:2983-5.

23. McWilliam H, Li W, Uludag M, Squizzato S, Park YM, Buso N, Cowley AP, Lopez R. Analysis tool web services from the EMBL-EBI. Nucleic Acids Res. 2013;41(Web Server issue):597-600.
24. Taylor SS, Kornev AP, Manuscript A. Protein kinases: evolution of dynamic regulatory proteins. Trends Biochem Sci. 2011;36:65-77.

25. EMBOSS: The European Molecular Biology Open Software Suite. https://www.ebi.ac.uk/Tools/psa/emboss needle/.

26. Eswar N, Eramian D, Webb B, Shen MY, Sali A. Protein structure modeling with MODELLER. Methods Mol Biol. 2008:426:145-159. doi:10.1007/978-160327-058-8_8. https://www.ncbi.nlm.nih.gov/pubmed/18542861.

27. Shen M-Y, Sali A. Statistical potential for assessment and prediction of protein structures. Protein Sci. 2006;15:2507-24.

28. Laskowski RA, MacArthur MW, Thornton JM. PROCHECK: validation of protein structure coordinates. In: Rossmann MG, Arnold ED, editors. International tables of crystallography, volume F. Crystallography of biological macromolecules. The Netherlands: Kluwer Academic Publishers; 2001. p. 722-5.

29. Baker NA, Sept D, Joseph S, Holst MJ, McCammon JA. Electrostatics of nanosystems: application to microtubules and the ribosome. Proc Natl Acad Sci. 2001;98(18):10037-41.

30. Morris GM, Huey R, Lindstrom W, Sanner MF, Belew RK, Goodsell DS, Olson AJ. AutoDock4 and AutoDockTools4: automated docking with selective receptor flexibility. J Comput Chem. 2009;30:2785-91.

31. Bateman A, Martin MJ, O'Donovan C, Magrane M, Apweiler R, Alpi E, Antunes R, Arganiska J, Bely B, Bingley M, Bonilla C, Britto R, Bursteinas B, Chavali G, Cibrian-Uhalte E, Da Silva A, De Giorgi M, Dogan T, Fazzini F, Gane P, Castro LG, Garmiri P, Hatton-Ellis E, Hieta R, Huntley R, Legge D, Liu W, Luo J, Macdougall A, Mutowo P, et al. UniProt: a hub for protein information. Nucleic Acids Res. 2015;43:D204-12.

32. Systèmes D: Dassault Systèmes BIOVIA, discovery studio modeling environment, release 2016. 2016.

33. Jakalian A, Bush BL, Jack DB, Bayly Cl. Fast, efficient generation of highquality atomic charges. AM1-BCC model: I. Method. J Comput Chem. 2000; 21:132-46.

34. Case DA, Betz RM, Botello-Smith W, Cerutti DS, Cheatham III TE, Darden TA, Duke RE, Giese TJ, Gohlke H, Goetz AW, Homeyer N, Izadi S, Janowski P, Kaus J, Kovalenko A, Lee TS, LeGrand S, Li P, Lin C, Luchko T, Luo R, Madej B, Mermelstein D, Merz KM, Monard G, Nguyen H, Nguyen HT, Omelyan I, Onufriev A, Roe DR, et al: Amber 2016. 2016.

35. Wang JM, Wolf RM, Caldwell JW, Kollman P a, Case D a: Development and testing of a general amber force field. J Comput Chem. 2004;25:1157-174.

36. Maier JA, Martinez C, Kasavajhala K, Wickstrom L, Hauser KE, Simmerling C. ff14SB: improving the accuracy of protein side chain and backbone parameters from ff99SB. J Chem Theory Comput. 2015;11:3696-713.

37. Homeyer $\mathrm{N}$, Horn AHC, Lanig H, Sticht $\mathrm{H}$. Amber force-field parameters for phosphorylated amino acids in different protonation states: Phosphoserine, phosphothreonine, phosphotyrosine, and phosphohistidine. J Mol Model. 2006:12:281-9.

38. Homeyer N, Gohlke H. FEW: a workflow tool for free energy calculations of ligand binding. J Comput Chem. 2013;34:965-73.

39. Fisette $\mathrm{O}$, Wingbermühle $\mathrm{S}$, Tampé $\mathrm{R}$, Schäfer LV. Molecular mechanism of peptide editing in the tapasin-MHC I complex. Sci Rep. 2016;6(November 2015):19085

40. Kumar A, Cocco E, Atzori L, Marrosu MG, Pieroni E. Structural and dynamical insights on HLA-DR2 complexes that confer susceptibility to multiple sclerosis in sardinia: a molecular dynamics simulation study. PLoS One. 2013;8:1-13.

41. Ryckaert J-P, Ciccotti G, Berendsen HJC. Numerical integration of the cartesian equations of motion of a system with constraints: molecular dynamics of n-alkanes. J Comput Phys. 1977;23:327-41.

42. Berendsen HJC, Postma JPM, van Gunsteren WF, DiNola A, Haak JR. Molecular dynamics with coupling to an external bath. J Chem Phys. 1984; 81:3684-90

43. Larini L, Mannella R, Leporini D. Langevin stabilization of moleculardynamics simulations of polymers by means of quasisymplectic algorithms. J Chem Phys. 2007;126:104101.

44. Gohlke H, Case D a, Biology M, Scripps T, Rd NTP. Converging free energy estimates: MM-PB(GB)SA studies on the protein-protein complex Ras-Raf. J Comput Chem. 2004;25:238-50.

45. Miller BR, McGee TD, Swails JM, Homeyer N, Gohlke H, Roitberg AE. MMPBSA.Py: an efficient program for end-state free energy calculations. J Chem Theory Comput. 2012;8:3314-21.

46. Weiser J, Shenkin PS, Still WC, Lcpo O, Shenkin PS, Still WC. Approximate atomic surfaces from linear combinations of pairwise overlaps (LCPO). J Comput Chem. 1999;20:217-30. 
47. Wickham H. ggplot2: Elegant Graphics for Data Analysis. Springer-Verlag New York, 2009.

48. R Core Team. R: A language and environment for statistical computing. Vienna, Austria: R Found Stat Comput; 2015.

49. Law V, Knox C, Djoumbou Y, Jewison T, Guo AC, Liu Y, Maciejewski A, Arndt D, Wilson M, Neveu V, Tang A, Gabriel G, Ly C, Adamjee S, Dame ZT, Han B, Zhou Y, Wishart DS. DrugBank 4.0: shedding new light on drug metabolism. Nucleic Acids Res. 2014;42(Database issue):D1091-7.

50. Hagmann WK. The many roles for fluorine in medicinal chemistry. J Med Chem. 2008;51:4359-69.

Submit your next manuscript to BioMed Central and we will help you at every step:

- We accept pre-submission inquiries

- Our selector tool helps you to find the most relevant journal

- We provide round the clock customer support

- Convenient online submission

- Thorough peer review

- Inclusion in PubMed and all major indexing services

- Maximum visibility for your research

Submit your manuscript at www.biomedcentral.com/submit
Biomed Central 